\title{
The Implications of Trust in the Sharing Economy - An Empirical Analysis of Uber
}

\author{
Christoph Mittendorf \\ Goethe University Frankfurt \\ mittendorf@wiwi.uni-frankfurt.de
}

\begin{abstract}
Modern technologies, including mobile applications and Internet-based platforms, continuously foster the rise of the sharing economy. In this paper, we focus on Uber, a ridesharing platform that is one of the fastest growing startups worldwide. We take the perspective of a potential customer and investigate the implications of trust. In particular, we modify a research model by Gefen (2000) and investigate the influence of trust on the customers' intentions: 'Inquire about drivers' and 'Request a ride'. In this regard, we differentiate between 'Trust in Uber' and 'Trust in drivers', while incorporating the two antecedents: 'Disposition to trust' and 'Familiarity with Uber'. The study employs survey data $(n=221)$ and structural equation modeling (CB-SEM). Our results provide empirical evidence that 'Trust in Uber' influences the customers' intentions, whereas the influence of 'Trust in drivers' is insignificant.
\end{abstract}

\section{Introduction}

Attitudes towards consumption have shifted in recent years making the sharing economy increasingly popular as an instrument to prevent unsustainable resource consumption and to improve resource allocation [4,5,22]. In addition, the proliferation of Internet-based platforms and mobile applications incessantly facilitates the rise of the sharing economy. Modern information and communications technologies allow people to disintermediate traditional commercial channels and to share excess capacity with each other effectively $[1,3]$. In this context, online platforms are often seen as the enablers of contemporary sharing economy services [22].

Previous research conceptualizes the concept of trust as a key component to establish a successful collaborative environment. For example, Morgan and Hunt (1994) identify trust as an important factor influencing cooperative activity. Following this logic, Ostrom (2000) finds trust and reciprocity to be essential to initiate and maintain $\mathrm{C} 2 \mathrm{C}$ relationships. Pavlou and Gefen (2002) further integrate institutionbased structures as an influential factor of trust in an intermediary framework. On the face of it, there is good reason to believe that trust is of high importance in the sharing economy.

The need for trust to establish online relationships, has been extensively elaborated in related online industries, for example, the e-commerce industry. However, existing theory is unable to fully explain the customers' intentions in the sharing environment, where users often get in contact with each other via an online platform and share a physical good in the offline world. In this regard, a comparative examination of intermediary and property provider trust in a sharing environment remains an open question. Answering this question is the first objective of our study. Therefore, we analyze the implications of trust on the customers' intentions on the sharing economy platform Uber. Uber is particularly suitable in the context as the mobile app connects complete strangers on short-term notice.

In particular, the goal of our study is to assess, whether 'trust in Uber' and 'trust in drivers' influence the customers' intentions to use the ridesharing service. In our paper, we close the existing research gap by answering the following research question: Does trust influence the customers' intentions on Uber?

We adopt the research model by Gefen (2000), which investigates the building and the implications of trust in the e-commerce industry. In addition, we follow the theory of 'Trust and Power' by Luhmann (1979), which comprises the fundamental conditions of trust. In this regard, we derive its validity from the sharing economy and propose a modified research model that seeks to explain the participation behavior in the ridesharing industry.

By doing so, we contribute to the field of IS by complementing the theory of trust-based decisionmaking on online platforms [14,30]. We further examine a possible trust transfer between the intermediary, hereinafter referred to as Uber, and the property providers, hereinafter referred to as drivers. 
By separating trust in Uber from trust in drivers we can further assess the influence of the respective trust construct on the customers' intentions which is more relevant in practice. Finally, by incorporating the antecedents 'disposition to trust' and 'familiarity' in temporary $\mathrm{C} 2 \mathrm{C}$ relationships, we also contribute to the sharing economy research by incorporating an established trust-inducing design.

We expect that trust influences the customers' intentions to 'inquire about drivers' and to 'request a ride' on Uber. In addition, we expect that 'trust in Uber' and 'trust in drivers' are interconnected. Finally, we expect that the antecedents 'disposition to trust' and 'familiarity' are a precondition of trust in our sharing economy setup.

The remainder of this paper is structured as follows. In Section 2, we present the related work on the sharing economy, including the relevant literature on trust and the corresponding antecedents. In Section 3, we present the modified research model and introduce our research hypotheses. In Section 4, we demonstrate our research methodology and present the survey results. We conclude our paper by discussing the implications of our findings, limitations, and directions for future research.

\section{Related work}

\subsection{The sharing economy}

Contemporary sharing practices not only extend the current market demand by addressing the needs of potential customers, but also compete with existing firms over the available market share $[3,8]$. Hence, while using modern technology, they enter existing markets, providing goods and services over digital commercial channels. In addition, they often realize economic, cultural, and organizational benefits that could not be achieved with the traditional ownership practices [22]. As a result, they continuously outperform incumbent businesses, which only offer goods and services over obsolete commercial channels [22]. These sharing practices go by various names, such as "access-based consumption" [3], "collaborative consumption" [5], "commercial sharing systems" [46], "consumer participation" [11], "the mesh" [13], and "sharing economy" [1,36].

In this paper, we focus on the sharing economy. The sharing economy is based on a hybrid market model that can nowadays be found in numerous industries [50]. In this regard, the most profound market changes can be observed in the hospitality $[50,53]$ and transportation industry $[1,7]$. In the following, we focus on Uber, an online platform that enables its user to offer, share, and request a ride. As a consequence, we exclude all other sharing economy platforms that focus on other industries, apply uncompensated sharing practices, or offer incomparable goods and services.

\subsection{Trust}

Trust is a complex concept that has been studied incessantly from different perspectives in various disciplinary fields [38]. In the following, we understand trust as an attribute that originates through relationships among different parties $[34,35]$. Based on this logic, researchers have shown that trust is crucial in interpersonal and commercial relationships [38,41] that involve risk, uncertainty, or interdependencies [24]. The need for trust is particularly high in socially distant relationships, such as in the online environment, due to an increasing transaction complexity [27]. Hence, online interactions that cannot be fully controlled by the individuals require an adequate trust basis to function successfully [54]. With the absence of trust, in order to reduce uncertainty, individuals would need to consider the entire action set of a counterpart [34]. As a consequence, individuals would rather refrain from an interaction than to evaluate all outcome possibilities [14].

Trust is among the most effective complexityreduction mechanisms, as it eliminates negative outcome possibilities from a consideration set [35]. Following this logic, with the rising dependency on other individuals and growing vulnerability to their misconduct, the need for trust increases [10,35]. Researchers argue that trust is particularly important in the online environment, such as in e-commerce $[39,45]$, crowdsourcing [54], and virtual teams [26]. However, there is scarce literature on the implications of trust in the sharing economy, in particular the ridesharing industry. We believe that the combination of peculiarities of Uber, such as one-time shared rides on short notice between private individuals, the usage of a mobile application, transparency of demographic data and GPS location, interactions with strangers, and the intermediary framework, have an extensive effect on the implications of trust [6,28].

Besides, previous research shows mixed results on the implications of trust in intermediary frameworks. For example, Verhagen et al. (2006) revealed a significant direct effect of seller trust on people's attitude towards purchasing on C2C online marketplaces; however, Hong et al. (2011) found that consumer behavior is largely determined by a trustworthy platform and not seller trust on B2C electronic markets. Accordingly, we draw the conclusion that the implications of intermediary trust and provider trust are influenced by the underlying 
relationship framework [45]. Uber, on the other hand, is an example of a $\mathrm{C} 2 \mathrm{C}$ business with a commercial focus where customers expect a business-like treatment. Existing theory has difficulty to predict the implications of trust in such a framework.

The findings in current literature, together with the peculiarities in our sharing economy setup, encouraged us to review the implications of trust for temporal ridesharing activities on Uber.

\subsection{Familiarity}

Existing literature demonstrates that trust aims at current and future interactions [28,32], whereas familiarity is based on previous interactions and experiences [29,33]. In this regard, familiarity serves as a precondition for trust. It allows comparatively safe expectations about the future and therefore complements trust as a complexity-reduction method $[20,35,47]$. As a result, familiarity helps to provide context that allows individuals to clarify future expectations [14].

Whereas, familiarity with Uber can be easily established through ongoing interactions with the mobile application, familiarity with specific drivers remains an exception, due to mostly non-recurring interactions. With the introduction of familiarity to our intermediary framework, we follow Gefen's (2000) call to test the antecedent in a different online context.

\subsection{Disposition to trust}

Disposition to trust, in contrast to familiarity, is not formed by ongoing interactions [14,30]. Accordingly, disposition to trust is not affected by previous experiences [19]. Based on literature, disposition to trust is a personality construct with two components: faith in humanity and trusting stance $[14,30,38]$. In this regard, personal faith in humanity assesses that other entities are usually upright, well-meaning, and dependable, whereas a trusting stance assesses the belief in superior outcomes when interacting with other people [19].

Disposition to trust serves as an antecedent of trust $[14,17]$ and is the result of lifelong personal development, education, and cultural consistency $[14,30]$. Therefore, with the absence of direct experience, disposition to trust is highly effective in the initiation phase of an interaction $[14,40]$. This makes disposition to trust especially valuable in an one-time interaction framework [52]. The paper builds on the above literature by positioning both disposition to trust and familiarity as key antecedents of trust in our sharing economy setup.

\section{Hypothesis development and research model}

In order to close the formulated research gap, we introduce a research model that allows us to analyze the impact of disposition to trust and familiarity on the respective trust construct, the dependency between trust in Uber and trust in drivers, as well as their influence on the customers' intentions. In particular, we focus on Uber, a well-known sharing economy platform, which was among the pioneers of the sharing economy. Therefore, we take the perspective of a customer respectively a potential passenger on Uber.

Ridesharing activities on Uber are generally defined as interactions with strangers that imply high levels of complexity and risk [5,50]. In this paper, we apply the complexity-reduction mechanisms suggested by Luhmann (1979) and adopt Gefen's research model of the e-commerce industry [14]. We follow the understanding that disposition to trust and familiarity can build trust by detracting the likelihood of individuals and intermediaries engaging in undesirable future actions [14,20]. Whereas familiarity receives specific modifications to reflect the sharing economy peculiarities of Uber, disposition to trust is adopted without any changes from previous research. In addition, we separate trust in drivers and trust in Uber from each other. With the introduction of the two individual trust constructs, we are able observe a possible connection between trust in Uber and trust in drivers, as well as their distinct implications.

In particular, we analyze the implications of the two trust constructs on the customers' intentions to inquire about drivers and to request a ride on Uber. In this specific context, to inquire about drivers implies using the Uber app to search for favorable drivers based on individual preferences. This involves reviewing the actual driver, including their name, photo, availability, and rating, as well as the car type and the license plate number. To request a ride, on the other hand, indicates the desire to receive a transportation service to a specific location. After the driver choice is made and the request has been processed by the app, personal information, pick-up location, and final destination are sent to the driver, who can either accept or deny the transportation request. In case the driver accepts the transportation request, Uber executes the booking and sends a confirmation to both parties including the transportation details. 
Table 1. Summary of key constructs

\begin{tabular}{|l|l|l|}
\hline Construct & Description & Key reference \\
\hline $\begin{array}{l}\text { Familiarity with } \\
\text { Uber }\end{array}$ & $\begin{array}{l}\text { Understanding of Uber, including knowledge about the app interface, } \\
\text { functions and available services, based on previous interactions and } \\
\text { experiences with Uber. }\end{array}$ & {$[14,27,34]$} \\
\hline Disposition to trust & $\begin{array}{l}\text { General faith in humanity and the belief that other people are in general } \\
\text { well-meaning and reliable. }\end{array}$ & {$[14,30,38]$} \\
\hline Trust in Uber & $\begin{array}{l}\text { Confidence that Uber will behave in a favorable way, which makes } \\
\text { users comfortable to use the app and helps them to overcome } \\
\text { perceptions of risk and insecurity. }\end{array}$ & {$[6,31]$} \\
\hline Trust in drivers & $\begin{array}{l}\text { Willingness to rely on favorable future actions of drivers to overcome } \\
\text { perceptions of risk and insecurity. }\end{array}$ & {$[6,31,50]$} \\
\hline $\begin{array}{l}\text { Inquire about } \\
\text { drivers }\end{array}$ & The intention of using the Uber app to search for drivers. & {$[9,15,43]$} \\
\hline Request a ride & The intention of requesting a ride to a specific location on the Uber app. & \\
\hline
\end{tabular}

Familiarity with Uber can build trust when effort, complexity, and uncertainty are reduced by applying a previously learned behavior $[29,33]$. For example, a customer is familiar with Uber when he is able to recall and apply past experiences of how to use the Uber app. However, if the results do not meet the customers' expectations, familiarity can vanish and complexity increases [14]. We assume in this study that familiarity with Uber increases with successful interactions, hence obtaining knowledge about the mobile app. As a result, high degrees of familiarity improve the customers' ability to maintain clear beliefs of what constitutes their expectations of favorable platform usage.

H1. Increased degrees of familiarity with Uber will increase the customers' trust in Uber.

Trust in drivers or the sharing economy platform is among other things determined by a general trusting disposition. Whereas humans have a natural disposition to trust and ability to judge trustworthiness, research tells us that disposition to trust is the tendency to believe in the integrity of other entities $[37,38]$. Although the effect can vary depending on the environment [40], in general, people of high disposition to trust are more inclined to frame positive initial interactions with an unfamiliar counterpart [52]. In our research model the antecedent, disposition to trust, directly affects the two trust constructs - trust in Uber and trust in drivers.

H2. The stronger the customers' disposition to trust is, the more they will trust in Uber.

H3. The stronger the customers' disposition to trust is, the more they will trust in drivers on Uber.

Another goal of our study is to find out, whether there is a trust transfer between trust in Uber and trust in drivers. We base our assumption on existing literature that argues that trust in users of an online platform is established by trusting the underlying platform [23,48,51]. For example, Pavlou and Gefen (2002) argue that a trustworthy intermediary helps to build buyer's trust in a community of sellers, while reducing perceived risk. Verhagen et al. (2006) show similar results and demonstrate that trust is transferred from the intermediary to the sellers in the e-commerce industry.

Therefore, we assume that increased trust in Uber does influence the customers' perception of trustworthy drivers. Following this logic, we find that in order to register on Uber, drivers have to accept the platform's general terms of conduct. These allow Uber to perform driver screenings, which include the inspection of criminal records, the inspection of motor vehicle records, as well as a regular evaluation of passenger feedback. As a result, Uber continuously removes distrustful drivers and blocks drivers that are conspicuous or commit misconduct. Furthermore, Uber builds trust by providing an end-to-end insurance protecting customers and drivers [18]. We follow previous research and assume that trust in Uber affects trust in drivers.

H4. Increased degrees of trust in Uber will increase the customers' trust in drivers.

Further, we assume that trust influences the customers' intentions to perform certain actions on Uber [43]. In practice, customers have the possibility to inquire about the drivers on Uber. Given this context, we hypothesize that the customers' intention to browse the platform for potential drivers rises with increased degrees of trust [6,28].

H5. Increased degrees of trust in Uber will increase the customers' intentions to inquire about drivers on Uber. 
H6. Increased degrees of trust in drivers will increase the customers' intentions to inquire about drivers on Uber.

To request a ride to a specific location at a specific time, usually completes the customers' search approach. In our study, we assume that customers trusting in Uber and trusting in drivers are more likely to request a ride on Uber. Furthermore, we believe that the need for trust is lower for inquiring about potential drivers on Uber than to request a ride.

H7. Increased degrees of trust in Uber will increase the customers' intentions to request a ride on Uber.

H8. Increased degrees of trust in drivers will increase the customers' intentions to request a ride on Uber.

Figure 1. Research model

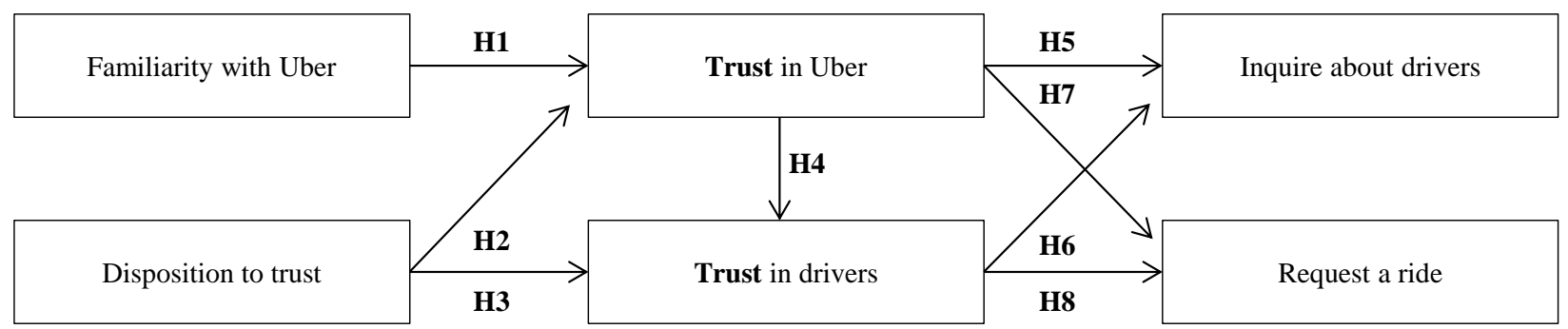

\section{Research method}

\subsection{Instrument development and data collection}

The questionnaire was specifically designed to measure the formation and the implications of trust on Uber from a customer's perspective. As explained earlier, we differentiated between trust in Uber and trust in drivers. Our questionnaire contained 37 questions, covering six constructs and demographic data. The response format was standardized using a 5point Likert scale ranging from "strongly disagree" (1) to "strongly agree" (5). Table 2 provides an overview of the final item catalogue, including the constructs and the respective item codes.

We conducted the entire survey in early 2016. By the due date, 221 participants completed the questionnaire. The respondents were mostly between $18-24$ years $(n=120), 25-34$ years $(n=55)$, or $35-44$ years $(n=23)$. About $46 \%$ of the participants were women $(n=101)$ and $54 \%$ were men $(n=120)$.

Table 2. Overview of items after the content validity assessment

\begin{tabular}{|l|l|l|}
\hline Construct & Code & Item \\
\hline \multirow{4}{*}{ Familiarity with } & Fam1 & I am familiar with using Uber. \\
\cline { 2 - 3 } & Fam2 & I am familiar with the interface of Uber. \\
\cline { 2 - 3 } & Fam3 & I am familiar with Uber. \\
\cline { 2 - 3 } & Fam4 & I am familiar with the intentions of Uber. \\
\cline { 2 - 3 } & Fam5 & I am familiar with the services Uber provides. \\
\hline \multirow{5}{*}{ Disposition to trust } & DisTr1 & I generally trust other people. \\
\cline { 2 - 3 } & DisTr2 & I generally have faith in humanity. \\
\cline { 2 - 3 } & DisTr3 & I generally trust other people unless they give me reason not to. \\
\cline { 2 - 3 } & DisTr4 & I feel that people are generally reliable. \\
\cline { 2 - 3 } & DisTr5 & I tend to count upon other people. \\
\hline \multirow{5}{*}{ Trust in Uber } & TrUb1 & I feel that Uber is honest. \\
\cline { 2 - 3 } & TrUb2 & I believe that Uber is trustworthy. \\
\cline { 2 - 3 } & TrUb3 & I trust Uber. \\
\cline { 2 - 3 } & TrUb4 & I feel Uber is reliable. \\
\cline { 2 - 3 } & TrUb5 & Even if not monitored, I would trust Uber to do the right job. \\
\hline \multirow{5}{*}{ Trust in drivers } & TrDr1 & I trust the drivers using Uber. \\
\cline { 2 - 3 } & TrDr2 & I believe that the drivers on Uber are trustworthy. \\
\cline { 2 - 3 } & TrDr3 & I feel that drivers on Uber are honest. \\
\cline { 2 - 3 } & TrDr4 & I feel drivers on Uber are reliable. \\
\cline { 2 - 3 } & TrDr5 & Even if not monitored, I would trust drivers on Uber. \\
\hline
\end{tabular}




\begin{tabular}{|l|l|l|}
\hline \multirow{4}{*}{$\begin{array}{l}\text { Inquire about } \\
\text { drivers }\end{array}$} & Inq1 & I would use Uber to inquire about the price of a ride. \\
\cline { 2 - 3 } & Inq2 & I would use Uber to inquire about rides in general. \\
\cline { 2 - 3 } & Inq3 & I would use Uber to inquire about drivers. \\
\cline { 2 - 3 } & Inq4 & I would not hesitate to inquire about rides on Uber. \\
\cline { 2 - 3 } & Inq5 & I would use Uber to inquire about the availability of drivers. \\
\hline \multirow{4}{*}{ Request a ride } & Req1 & I would feel comfortable requesting a ride on Uber. \\
\cline { 2 - 3 } & Req2 & I am very likely to request a booking on Uber in the future. \\
\cline { 2 - 3 } & Req3 & I would request a ride on Uber in general. \\
\cline { 2 - 3 } & Req4 & I would not hesitate to request a ride on Uber. \\
\cline { 2 - 3 } & Req5 & I would use Uber to request a ride to a specific location. \\
\hline
\end{tabular}

\section{Data analysis and results}

\subsection{Measurement model}

The data was analyzed with SPSS Statistics 19.0.0 for Windows and AMOS 16.0.1. We used the SPSS package to test the reliability of the measurement model, as well as to perform a factor analysis, and covariance-based structural equation modeling (CBSEM).
We examined the reliability and validity of the constructs. Internal consistency was assessed by following the guidelines from Straub et al. (2004), and Hair et al. (2010). Cronbach's alpha and the Composite Reliability need to be above 0.70 in order to indicate sufficient reliability $[2,12]$. Table 3 shows that all our construct obtained Cronbach's alpha and Composite Reliability scores above the threshold of 0.70 .

Table 3. Descriptive statistics and reliability indices for constructs

\begin{tabular}{|l|c|c|c|c|c|c|}
\hline & DisTr & Fam & TrUb & TrDr & Inq & Req \\
\hline Mean & 3.195 & 2.417 & 2.975 & 2.970 & 3.258 & 3.221 \\
\hline Standard Deviation & 1.058 & 1.567 & 1.060 & 1.000 & 1.268 & 1.290 \\
\hline Cronbach's Alpha (a) & 0.868 & 0.926 & 0.949 & 0.913 & 0.939 & 0.946 \\
\hline Composite Reliability & 0.871 & 0.920 & 0.952 & 0.910 & 0.935 & 0.947 \\
\hline
\end{tabular}

We assessed construct validity by evaluating convergent validity [42] and discriminant validity [49]. In general, convergent validity is considered acceptable when the Average Variance Extracted (AVE) values successfully exceed the threshold of 0.50 for all constructs $[12,19]$, which indicates that more than $50 \%$ of the variance of the measurement items can be accounted for by the constructs [30]. All our constructs reached the given threshold. Therefore, we could claim convergent validity for our measurement model.

Discriminant validity means the degree to which measures of different latent variables are unique [42].
In general, discriminant validity is considered acceptable when the square roots of the AVE are greater than the correlations between the research constructs. Table 4 indicates that there are no outliers and all the square roots of the AVE are greater than all cross-correlations, hence indicating that the variance explained by each construct is much larger than the measurement error variance [44]. Furthermore, discriminant validity was established where the Average Shared Squared Variance (ASV) and the Maximum Shared Variance (MSV) are both lower than the AVE for all the constructs [21].

Table 4. Convergent and discriminant validity coefficients

\begin{tabular}{|l|c|c|c||c|c|c|c|c|c|}
\hline & AVE & MSV & ASV & Req & Fam & TrUb & TrDr & Inq & DisTr \\
\hline Req & 0.781 & 0.733 & 0.355 & $\mathbf{0 . 8 8 4}$ & & & & & \\
\hline Fam & 0.701 & 0.307 & 0.197 & 0.519 & $\mathbf{0 . 8 3 8}$ & & & & \\
\hline TrUb & 0.800 & 0.434 & 0.320 & 0.659 & 0.554 & $\mathbf{0 . 8 9 4}$ & & & \\
\hline TrDr & 0.674 & 0.399 & 0.243 & 0.506 & 0.405 & 0.632 & $\mathbf{0 . 8 2 1}$ & & \\
\hline Inq & 0.743 & 0.733 & 0.303 & 0.756 & 0.463 & 0.580 & 0.435 & $\mathbf{0 . 8 6 2}$ & \\
\hline DisTr & 0.575 & 0.205 & 0.097 & 0.288 & 0.174 & 0.353 & 0.453 & 0.200 & $\mathbf{0 . 7 5 9}$ \\
\hline
\end{tabular}

Note: $\mathrm{AVE}=$ Average Variance Extracted, MSV = Maximum Shared Variance, ASV = Average Shared Squared Variance. Diagonal elements of the last six columns represent the square root of the AVE. Off diagonal elements are the correlations among latent constructs. 


\subsection{Structural model assessment}

To answer our research question, we confirmed the factor structure of our dataset with AMOS. We assessed the relationship between the antecedents and the trust constructs, as well as the implications of trust on the customer's intentions, performing structural equation modeling (SEM) [16]. In our analysis, we controlled for age, income, and gender, as source of differing results. The fit indices indicated an acceptable fit with CMIN/DF 1.958, CFI 0.942, RMSEA 0.066, and NFI $0.889[2,25]$. In addition, the coefficient of determination values (R2) were 0.410 (trust in Uber), 0.421 (trust in drivers), 0.343 (inquire about drivers), and 0.449 (request a ride), reflecting that the model provides sufficient explanations of the variance. The results of the SEM are presented in Figure 2.

Figure 2. AMOS analysis of the research model showing standardized coefficients

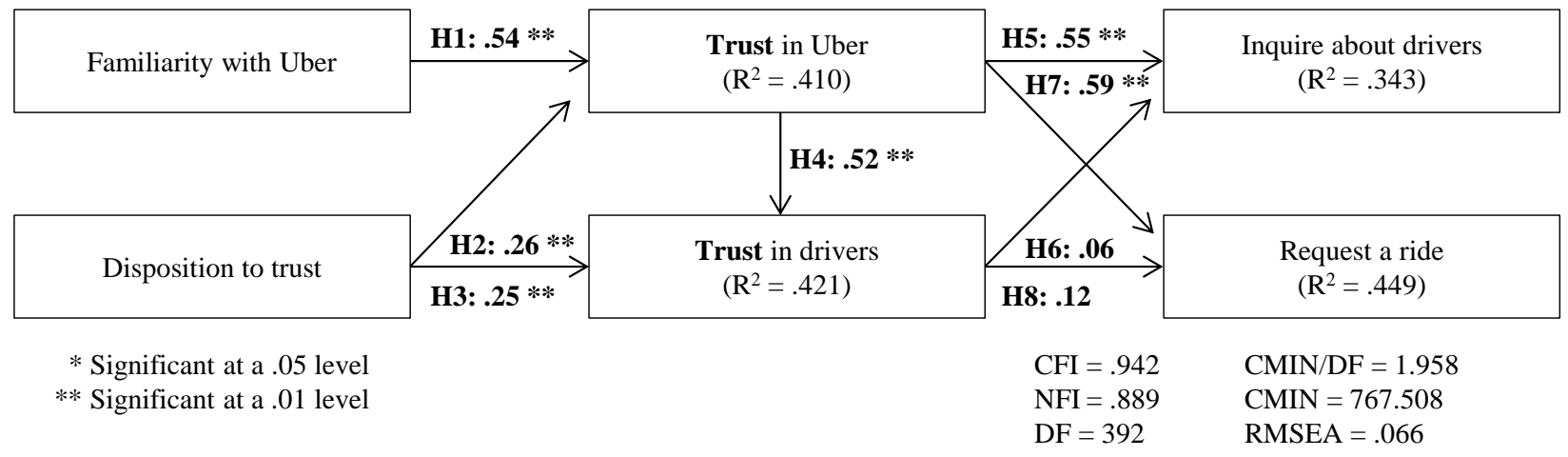

The results show support for six hypotheses. Disposition to trust affects both trust in Uber $(\mathrm{t}=4.92)$ and trust in drivers $(\mathrm{t}=3.79)$, supporting $\mathrm{H} 2$ and $\mathrm{H} 3$. Familiarity, on the other hand, affects trust in Uber $(\mathrm{t}=7.91)$, supporting $\mathrm{H} 1$. In addition, $\mathrm{H} 4$ is supported, demonstrating that trust in Uber has a significant effect on trust in drivers $(t=7.91)$. As postulated in $\mathrm{H} 5$ and $\mathrm{H} 7$, trust in Uber has a significant effect on both intentions - inquire about drivers $(\mathrm{t}=6.71)$ and request a ride $(\mathrm{t}=8.01)$. In contrast, we find that $\mathrm{H} 6$ and $\mathrm{H} 8$ are not supported inquire about drivers $(t=0.74)$ and request a ride $(\mathrm{t}=1.65)$.

\section{Table 5. Results of hypothesis testing}

\begin{tabular}{|c|c|c|c|c|}
\hline Hypothesis & SC & SE & CR & Result \\
\hline H1 & $.54^{* *}$ & .058 & 7.91 & Supported \\
\hline H2 & $.26^{* *}$ & .068 & 4.92 & Supported \\
\hline H3 & $.25^{* *}$ & .066 & 3.79 & Supported \\
\hline H4 & $.52^{* *}$ & .059 & 7.91 & Supported \\
\hline H5 & $.55^{* *}$ & .089 & 6.71 & Supported \\
\hline H6 & .06 & .094 & 0.74 & $\begin{array}{c}\text { Not } \\
\text { supported }\end{array}$ \\
\hline H7 & $.59^{* *}$ & .091 & 8.01 & Supported \\
\hline H8 & .12 & .097 & 1.65 & $\begin{array}{c}\text { Not } \\
\text { supported }\end{array}$ \\
\hline
\end{tabular}

Note: $\mathrm{SC}=$ Standardized Coefficient,

$\mathrm{CR}=$ Critical Ratio, $\mathrm{SE}=$ Standardized Error,

** Significant at a .01 level
The data analysis answered our research question. Both antecedents influence their respective trust construct. In addition, our results show a relationship between trust in Uber and trust in drivers. Whereas there is evidence that trust in Uber affects the customers intentions to inquire about drivers and to request a ride, trust in drivers shows no significant influence on the customers' intentions. Table 5 shows a summary of the study results.

\section{Discussion}

Our research attempts to understand the implications of trust in the ridesharing industry. In our study, we took the perspective of a potential customer. We analyzed how platform and provider trust influence the customers' intentions on Uber. In this regard, Uber is particularly interesting as the mobile app allows complete strangers to get in contact with each other in the online world and to share a ride on short-term notice in the offline world. In order to perform the analysis, we modified the research model from Gefen (2000) by separating trust in the intermediary from trust in the provider.

\subsection{Research implications}

Our study contributes to research in several ways. First, we could show that platform trust does influence the customers' intentions in our sharing economy setup. Our hypotheses regarding the effect of trust in Uber are supported for both tested 
intentions - to inquire about drivers and to request a ride. On the other hand, our findings indicate that trust in drivers has no significant effect on the customers' intentions on Uber. Whereas our findings seem surprising at first, as Uber connects complete strangers with each other, it seems likely most of the risk is already covered by the intermediary. Accordingly, we can argue that our findings are in line with the work of Hong et al. (2011) of the B2C e-commerce industry, which demonstrate that seller trust has no effect on the customers' purchase intentions. Therefore, our results are not in line with the findings of Verhagen et al. (2000), which identified seller trust as an important driver of customers' intentions in $\mathrm{C} 2 \mathrm{C}$ markets. Hence, the separation of trust into two separate constructs allowed us to show a deviating effect on the customers' intentions on Uber.

The reason why trust in drivers is not an influential factor of the customers' intentions in the sharing economy could have various reasons, which we recommend to examine in future research. Possible reasons are: 1. Ridesharing is only a temporary short-term service, which means that even on the off chance of a bad experience the perceived disservice is only of short duration. 2. It might be hard to judge for potential customers, based on the available information on Uber, whether drivers are upright and trustworthy. 3. Despite the C2C character, Uber has a commercial focus where customers can expect a business like treatment.

Second, we successfully addressed an existing research gap by analyzing the trust transfer between Uber and the drivers [6]. Whereas, we cannot clarify the direction of the trust transfer, we extend the theoretical background of the sharing economy by examining the phenomenon of trust transfer in our particular intermediary framework.

Third, we successfully assessed the effect of both antecedents, disposition to trust and familiarity, on their respective trust construct. Thus, by evaluating the two antecedents in an unprecedented online environment, we resolve limitations that have been frequently formulated by prior researchers $[14,29,35]$. Overall, our results complement the understanding of the sharing economy with focus on the ridesharing industry.

\subsection{Practical implications}

Our results offer important insights for managers of sharing economy services. In our study, trust in Uber appears to be the key driver of user intentions. Besides, forming the intention to use the mobile application, trust in Uber might also be of high relevance for the acquisition and the retention of customers. In practice, trust in Uber might entail providing personal information, such as demographics like age and nationality, as well as credit card information based on a credulous belief that the provided information will not be misused in any incongruous or unknown way by the platform provider. Therefore, we recommend Uber to increase trust in the platform, for example by providing adequate security measures, such as the extension of quality checks, advanced encryption of personal information, including location profiles, and demographics, as well as integrating a reliable support system in case of any challenges that might occur when using the mobile app. In addition, as familiarity seems to be an influential driver of platform trust, we recommend practitioners to pay attention to high quality applications, recognizable application interfaces, and transparent processes.

\subsection{Limitations}

Our study has some limitations. First, the sample size is fairly small. Whereas a sample size of 221 is generally acceptable, a larger sample would be preferable. Second, we only analyzed a specific sharing economy service in one particular market. Therefore, our study is context-dependent and it is unclear that our findings can be generalized for other sharing service, such as for Airbnb. Third, we only took the perspective of a potential customer on Uber. It might worthwhile to keep the study design and take the perspective of a potential driver. In this regard, it might be interesting to analyze the need of trust in passengers to form driver intentions on Uber. Fourth, given our study design, we could not verify the direction of the trust transfer between Uber and the drivers. It might be worth elaborating a possible reciprocal trust relationship in a consecutive study.

\section{Conclusion}

In this paper, we focused on Uber, a prominent example of the sharing economy. We took the perspective of a potential customer and investigated the concept of trust, which induces strangers to form temporal $\mathrm{C} 2 \mathrm{C}$ relationships on Uber. We adopted and modified the research model by Gefen (2000) and investigated the formation of trust by incorporating two antecedents. Furthermore, we differentiated between 'Trust in Uber' and 'Trust in drivers', and examined their implications on two customer intentions. To seek support for our research model, we conducted a survey with 221 participants. The results show trust in Uber is decisive to successfully 
form customer intentions, whereas the hypothesis regarding the influence of driver trust could not be supported. Overall, we are convinced that our findings are useful for IS researchers and practitioners.

\section{References}

[1] Andersson, M., Hjalmarsson, A., and Avital, M. Peerto-peer service sharing platforms: Driving share and share alike on a mass-scale. International Conference on Information Systems, (2013), 2964-2978.

[2] Bagozzi, R.P. and Yi, Y. On the Evaluation of Structural Equation Models. Journal of the Academy of Marketing Science 16, 1 (1988), 74-94.

[3] Bardhi, F. and Eckhardt, G.M. Access-Based Consumption: The Case of Car Sharing. Journal of Consumer Research 39, (2012), 881-898.

[4] Belk, R. You are what you can access: Sharing and collaborative consumption online. Journal of Business Research 67, 8 (2014), 1595-1600.

[5] Botsman, R. and Rogers, R. What's Mine Is Yours How Collaborative Consumption is Changing the Way we live. Collins, 2011.

[6] Chen, J., Zhang, C., and Xu, Y. The Role of Mutual Trust in Building Members' Loyalty to a C2C Platform Provider. International Journal of Electronic Commerce 14, 1 (2009), 147-171.

[7] Cohen, B. and Kietzmann, J. Ride On! Mobility Business Models for the Sharing Economy. Organization \& Environment 27, 3 (2014), 279-296.

[8] Cusumano, M.A. How traditional firms must compete in the sharing economy. Communications of the ACM 58, 1 (2014), 32-34.

[9] Davis, F., Bagozzi, R., and Warshaw, P. User acceptance of computer technology: a comparison of two theoretical models. Management science 35, 8 (1989), 9821003.

[10] Deutsch, M., Laboratories, T., and Hill, M. Trust and Suspicion. Journal of Conflict Resolution 2, 4 (1958), 265279.

[11] Fitzsimmons, J.A. Consumer Participation and Productivity in Service Operations. Interfaces 15, 3 (1985), 60-67.

[12] Fornell, C. and Larcker, D.F. Evaluating Structural Equation Models with Unobservable Variables and Measurement Error. Journal of Marketing Research 18, 1 (1981), 39-50.

[13] Gansky, L. The Mesh. Portfolio Penguin, 2010.
[14] Gefen, D. E-commerce: the role of familiarity and trust. Omega 28, 6 (2000), 725-737.

[15] Gefen, D., Karahanna, E., and Straub, D.W. Trust and TAM in Online Shopping: An integrated Model. MIS Quarterly 27, 1 (2003), 51-90.

[16] Gefen, D., Rigdon, E.E., and Straub, D.W. An Update and Extension to SEM Guidelines for Administrative and Social Science Research. MIS Quarterly 35, 2 (2011), iiixiv.

[17] Gefen, D. and Straub, D.W. Consumer trust in B2C eCommerce and the importance of social presence:

Experiments in e-Products and e-Services. Omega 32, 6 (2004), 407-424.

[18] Germann Molz, J. Social networking technologies and the moral economy of alternative tourism: The case of couchsurfing.org. Annals of Tourism Research 43, (2013), $210-230$

[19] Gounaris, S. and Dimitriadis, S. Assessing service quality on the Web: evidence from business-to-consumer portals. Journal of Services Marketing 17, (2003), 529548.

[20] Gulati, R. Does familiarity breed trust? the implications of repeated ties for contractual choice in alliances. Academy of Management Journal 38, 1 (1995), 85-112.

[21] Hair, J.F., Black, W.C., Babin, B.J., and Anderson, R.E. Multivariate Data Analysis. 2010.

[22] Hamari, J., Sjöklint, M., and Ukkonen, A. The Sharing Economy: Why People Participate in Collaborative Consumption. Journal of the Association for Information Science and Technology, (2015), 1-19.

[23] Hong, I.B. and Cho, H. The impact of consumer trust on attitudinal loyalty and purchase intentions in B2C emarketplaces: Intermediary trust vs. seller trust. International Journal of Information Management 31, 5 (2011), 469-479.

[24] Hosmer, L.T. Trust: The Connecting Link between Organizational Theory and Philosophical Ethics. The Academy of Management Review 20, 2 (1995), 379-403.

[25] Hu, L. and Bentler, P.M. Cutoff criteria for fit indexes in covariance structure analysis: Conventional criteria versus new alternatives. Structural Equation Modeling: A Multidisciplinary Journal 6, 1 (1999), 1-55.

[26] Jarvenpaa, S.L., Knoll, K., and Leidner, D.E. Is Anybody Out There? Antecedents of Trust in Global Virtual Teams. Journal of Management Information Systems 14, 4 (1998), 29-64.

[27] Jarvenpaa, S.L., Tractinsky, N., and Saarinen, L. Consumer trust in an internet store: a cross culture validation. Journal of Computer Mediated Communication 
5, (1999), 1-35.

[28] Jiang, Q., Huang, X., and Chen, Z. Antecedents and consequences of consumers' trust in electronic intermediaries: An empirical study of hotel booking websites. Frontiers of Business Research in China 3, 4 (2009), 647-666.

[29] Johnson, E.J. and Russo, J.E. Product Learning Familiarity New and Information. The Journal of Consumer Research 11, 1 (1984), 542-550.

[30] Kim, D.J., Ferrin, D.L., and Rao, H.R. A trust-based consumer decision-making model in electronic commerce: The role of trust, perceived risk, and their antecedents. Decision Support Systems 44, 2 (2008), 544-564.

[31] Kim, D.J., Ferrin, D.L., and Rao, H.R. A trust-based consumer decision-making model in electronic commerce: The role of trust, perceived risk, and their antecedents. Decision Support Systems 44, 2 (2008), 544-564.

[32] Koufaris, M. and Hampton-Sosa, W. The development of initial trust in an online company by new customers. Information \& Management 41, 3 (2004), 377-397.

[33] Lessig, P. V. and Park, W.C. Familiarity and Its Impact on Consumer Decision Biases and Heuristics. Journal of Consumer Research 8, 2 (1981), 223-231.

[34] Lewis, J.D., Weigert, A., and Dame, U.N. Trust as a Social Reality *. Oxford University Press 63, 4 (1985), 967-985.

[35] Luhmann, N. Trust and Power. John Wiley \& Sons, 1979.

[36] Malhotra, A. and Van Alstyne, M. The dark side of the sharing economy .... and how to lighten it. Communications of the ACM 57, 11 (2014), 24-27.

[37] Mayer, R.C., Davis, J.H., and Schoorman, F.D. An Integrative Model of Organizational Trust. Academy of Management Review 20, 3 (1995), 709-734.

[38] McKnight, D.H. and Chervany, N.L. What Trust Means in E-Commerce Customer Relationships: An Interdisciplinary Conceptual Typology. International Journal of Electronic Commerce 6, 2 (2001), 35-59.

[39] McKnight, D.H., Choudhury, V., and Kacmar, C. The impact of initial consumer trust on intentions to transact with web site: A trust building model. Journal of Strategic Information Systems 11, (2002), 297-323.

[40] McKnight, D.H., Choudhury, V., and Kacmar, C. Developing and validating trust measures for e-commerce: An integrative typology. Information Systems Research 13, 3 (2002), 334-359.

[41] Morgan, R.M. and Hunt, S.D. The Commitment-Trust - Theory of Relationship Marketing. Journal of Marketing 58, 3 (1994), 20-38.
[42] O'Leary-Kelly, S.W. and Vokurka, R.J. The empirical assessment of construct validity. Journal of Operations Management 16, 4 (1998), 387-405.

[43] Pavlou, P.A. Integrating Trust in Electronic Commerce with the Technology Acceptance Model: Model Development and Validation. AMCIS 2001, (2001), 816822.

[44] Pavlou, P.A. and Dimoka, A. The nature and role of feedback text comments in online marketplaces: Implications for trust building, price premiums and seller differentiation. Information Systems Research 17, 4 (2006), 392-414.

[45] Pavlou, P.A. and Gefen, D. Building Effective Online Marketplaces with Institution-Based Trust. Information Systems Research 15, 1 (2002), 667-675.

[46] Rose, R.L. and Lamberton, C.P. When Is Ours Better Than Mine? A Framework for Understanding and Altering Participation in Commercial Sharing Systems. Journal of Marketing 76, 4 (2012), 109-125.

[47] Rousseau, D.M., Sitkin, S.B., Burt, R.S., and Camerer, C. Not so different after all: A cross-discipline view of trust. Academy of Management Review 23, 3 (1998), 393404.

[48] Son, J. and Benbasat, I. Trust-building Measures In B2b Electronic Marketplaces. Communications of AIS 18, (2006), 2-52.

[49] Straub, D., Boudreau, M.-C., and Gefen, D. Validation Guidelines for Is Positivist Research. Communications of the Association for Information Systems 13, (2004), 380427.

[50] Tussyadiah, I.P. An Exploratory Study on Drivers and Deterrents of Collaborative Consumption in Travel. In Information \& Communication Technologies in Tourism 2015. 2015, 817-830.

[51] Verhagen, T., Meents, S., and Tan, Y.-H. Perceived risk and trust associated with purchasing at electronic marketplaces. European Journal of Information Systems 15, 6 (2006), 542-555.

[52] Wu, G., Hu, X., and Wu, Y. Effects of Perceived Interactivity, Perceived Web Assurance and Disposition to Trust on Initial Online Trust. Journal of ComputerMediated Communication 16, 1 (2010), 1-26.

[53] Zervas, G., Proserpio, D., and John, B. The Rise of the Sharing Economy: Estimating the Impact of Airbnb on the Hotel Industry. Boston University School of Management Research Paper Series 16, (2013), 1-36.

[54] Zheng, H., Li, D., and Hou, W. Task Design, Motivation, and Participation in Crowdsourcing Contests. International Journal of Electronic Commerce 15, 4 (2011), 57-88. 